\title{
Endodontic management of root perforating internal replacement resorption
}

\author{
Rustem Kemal Subay ${ }^{1}$, Melike Ordulu Subay ${ }^{2}$, Sirin Baloglu Tuzcu ${ }^{3}$
}

Correspondence: Dr. Rustem Kemal Subay

'Department of Endodontics, School of Dentistry, Istanbul Aydin University, Istanbul, Turkiye, ${ }^{2}$ Department of Oral and Maxillofacial Surgery, School of Dentistry, Istanbul University, Istanbul, Turkiye, Email: ctsubay@yahoo.com ${ }^{3}$ Private practice, Nisantasi, Istanbul, Turkiye

\section{ABSTRACT}

This case report presents the management of a case of rarely seen perforating internal replacement resorption using calcium hydroxide $(\mathrm{CH})$ medication and mineral trioxide aggregate (MTA) root canal obturation. A maxillary central incisor of a 20-year-old female was showing a sinus track on the mucosa. Radiographically, an irregularly shaped and perforating internal resorption area was seen at the middle third of the root canal. Appearances of the bone-like fuzzy material were observed inside the resorption site. The apical part of the canal was obliterated. Following 3 months of $\mathrm{CH}$ medication, the canal and the perforation were obturated with MTA filling. At 6-year follow-up, the tooth was clinically asymptomatic and showing radiographical appearances of the hard tissue repair, resembling a barrier and periodontal membrane healing around MTA at the perforation site.

Key words: Endodontic treatment, internal root replacement resorption, internal root resorption

\section{INTRODUCTION}

Clinically, internal root resorption is a rarely seen condition. ${ }^{[1]}$ Histologically, a part of the pulp tissue inside the root canal shows resorptive inflammatory changes involving dentin resorbing cells (odontoclasts) in the resorption lacunes. Predentin and odontoblasts were suggested as a protective layer against the internal resorption, inhibiting dentinoclast adherence to dentin tissue. If the pulp is not completely necrotized by advancing coronal infection, internal resorptive activity progressively resorbs the root canal dentin and eventually perforates the cementum. ${ }^{[2,3]}$

Two types of internal resorption were defined on the basis of histological observations as follows: internal inflammatory resorption (IIR) and internal replacement resorption (IRR). Radiographically, the IIR displays a

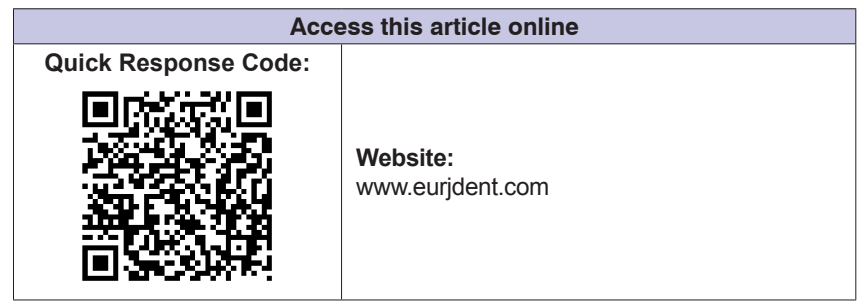

clear, oval-shaped radiolucent area around the root canal. In the IRR cases, an irregular enlargement of the root canal with the radiological appearances of a fuzzy material resembling the bone tissue might be observed. ${ }^{[2,3]}$

For treatment of perforating internal root resorption cases, mineral trioxide aggregate (MTA) might be preferred to fill the root defect and the canal. ${ }^{[4-7]}$ The removal of resorptive inflammatory tissue with the surgery and filling of root defect with MTA might be another treatment approach for the perforating cases. ${ }^{[8,9]}$

This case report presents orthograde management of a case of perforating IRR using MTA as a root canal filling.

This is an open access journal, and articles are distributed under the terms of the Creative Commons Attribution-NonCommercial-ShareAlike 4.0 License, which allows others to remix, tweak, and build upon the work non-commercially, as long as appropriate credit is given and the new creations are licensed under the identical terms.

For reprints contact: reprints@medknow.com

How to cite this article: Subay RK, Subay MO, Tuzcu SB. Endodontic
management of root perforating internal replacement resorption. Eur J
Dent 2018;12:450-3.
DOI: $10.4103 /$ ejd.ejd_31_17




\section{CASE REPORT}

A 20-year-old female presented to the Department of Endodontics, School of Dentistry, İstanbul University, with discomfort in her maxillary right central tooth. She reported a trauma on the right central tooth when was a child, causing a crown fracture.

A sinus tract was seen clinically on the midfacial attached gingiva of the right central tooth. A composite resin restoration was present on the tooth. Radiographic examination showed the presence of an irregular enlargement of the canal at the middle third root level. The enlarged part of the canal appeared to be filled by the fuzzy hard tissue material [Figure 1a]. The apical part of the root canal appeared to be obliterated, and no signs of apical pathosis were detected at the radiographies. An irregular rarefaction was present at the distal middle root wall, showing appearances of perforating internal root resorption. The patient declined the recommendation for cone-beam computed tomography diagnosis of the tooth.

Written consent was obtained from the patient. The patient's medical history was noncontributary. Following local infiltration anesthesia (Ultracaine D-S, Sanofi, Kırklareli, Turkey) and the placement of a rubber dam, the root canal was accessed. Working length determination with an apex locator (Propex II, Dentsply, US) showed beyond the foramen

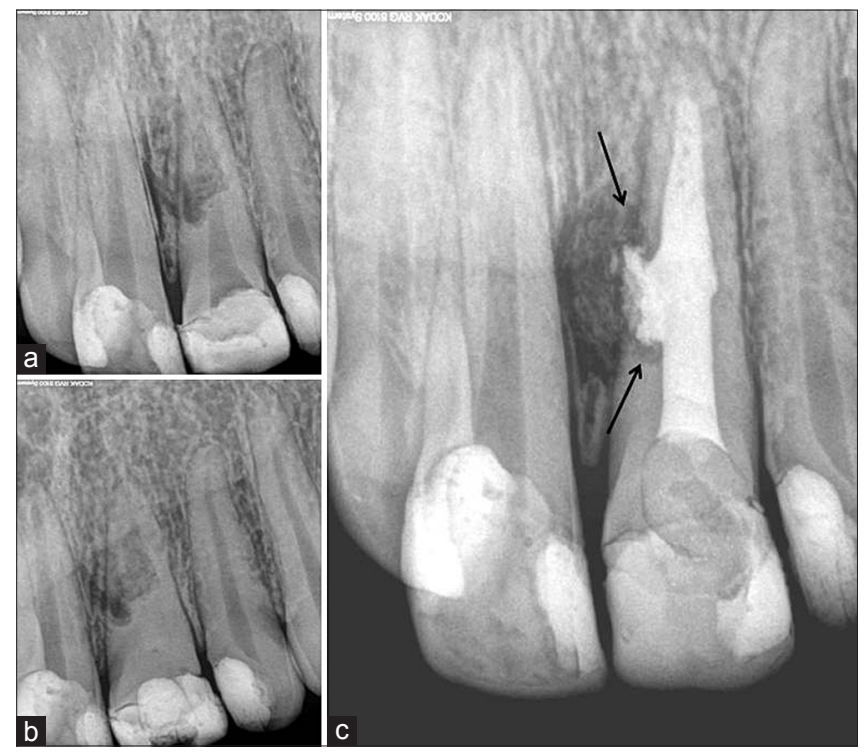

Figure 1: (a) Preoperative radiography of the case showing internal replacement resorption. Note the appearance of irregular enlargement at the middle third of the canal that was filled with a fuzzy material resembling the bone-like tissue. (b) Calcium hydroxide medication at 1-month follow-up. (c) After canal filling with mineral trioxide aggregate. Note the gaps between mineral trioxide aggregate and the resorbed root walls (arrows) signals when the file tip was at the middle third root level. Working length was determined with a K-file $(21 \mathrm{~mm})$ with digital periapical radiography. After the copious irrigation with saline solution, a conservative filing was applied to the canal walls. Bleeding was present from the canal during instrumentation. The canal was medicated with calcium hydroxide $(\mathrm{CH})$ mixed with saline (Sultan Dental, NY, US) using a lentulo. The cavity was sealed with a temporary filling (Coltosol, Vigodent, Bonsucesso, Brazil). Following copious irrigation with $5 \% \mathrm{NaOCl}, \mathrm{CH}$ powder-saline mixture was renewed after a week. The healing of sinus tract was observed at the 1-month visit. The exudation from the canal was continuing, and $\mathrm{CH}$ was placed into the canal after the irrigation [Figure 1b]. $\mathrm{CH}$ dressing was renewed two times in 2 months due to the exudation in the canal.

At the 3-month visit, white MTA (ProRoot MTA, Dentsply, TN, US) was prepared according to the manufacturer's recommendations and filled incrementally to the canal orifice with vertical condensation using the pluggers. Intraoperative radiographies revealed that MTA filled the canal and the resorption defect. A wet cotton pellet was put on the MTA, and the cavity was sealed with the temporary restorative material. After 3 days, the cavity was restored using an anterior composite resin filling (Supreme, 3M ESPE, Dental Products, MN, USA), [Figure 1c].

At the time of the 6-and 12-month follow-ups, organization of the periradicular tissues around the perforation site and progressive deposition of hard tissue between the MTA and the defect margins were seen, radiographically. The patient missed the 2-year follow-up. An orthodontist phoned for the consultation of the orthodontic treatment that was planned for the patient. During the 4-year follow-up examinations, the tooth was free of endodontic and periodontal symptoms. Radiographically, the gaps were seen as completely repaired with the deposition of hard tissue [Figure 2a]. After the completion of a year-long orthodontic treatment, all incisors were restored with full esthetic ceramic crowns by a prosthodontist due to the patient's complaints about the occurrence of discoloration in the tooth [Figure $3 a$ and $b$ ]. The prosthodontist reported that a fiber post was bonded to the canal, and a composite core was built up. At 6-year follow-up radiographs, the healing with hard tissue repair resembling a barrier on the MTA and the organization of periodontal membrane adjacent to this hard tissue barrier were seen [Figure 2b]. 


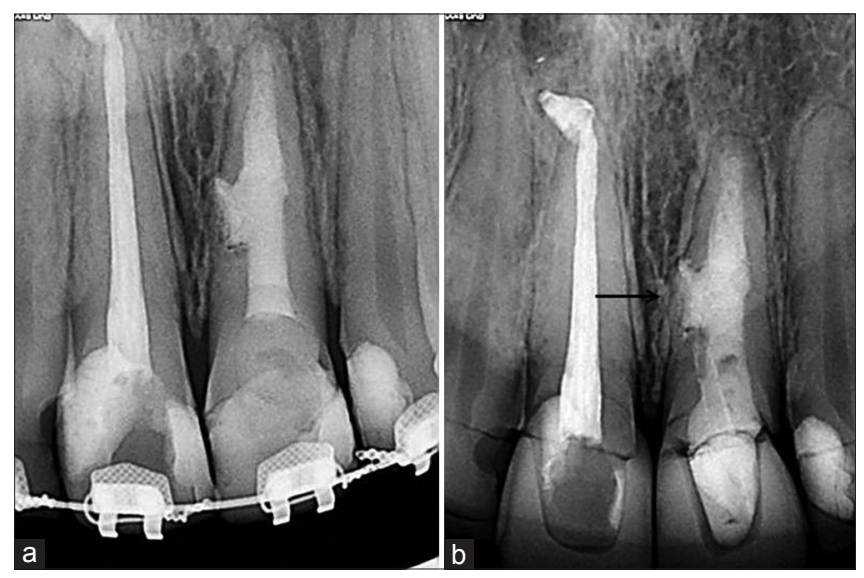

Figure 2: (a) Four-year follow-up radiograph. (b) Six-year follow-up radiograph showing a thick and complete hard tissue barrier on mineral trioxide aggregate (arrow)

\section{DISCUSSION}

The clinical manifestations of the presented case herein appeared that the tooth was showing an IRR with perforation to the surrounding tissues. The case featured an irregular enlargement in the middle third of the root canal, which was filled with a fuzzy material resembling the radiographic appearances of bone.

Histologically, the resorptive activity of odontoclasts in IRR cases causes defects in the intraradicular dentin tissue concomitant with the deposition of metaplastic bone-like hard tissue in some areas of the defect. As a result, an irregularly shaped resorption defect occurs in the dentin walls of the affected canal region..$^{[2,3]}$

Patel et al. ${ }^{[2]}$ noted that the ultimate treatment modality for the treatment of perforating IR cases is the conventional endodontic therapy. Nilsson et al..$^{[3]}$ suggested the surgical approach with the use of MTA or calcium silicate cements for the filling as a second intention in cases in which it is not possible to manage the lesion through the canal. Altundasar and Demir ${ }^{[8]}$ treated successfully perforating internal resorption cases using MTA and periodontal surgery with graft materials in single treatment sessions. The long-term successful clinical and radiological results of this case favor nonsurgical endodontic management for the perforating internal resorption cases. The surgical approach in the treatment of perforating internal resorptions might be used when an excessive extrusion of the MTA filling occurs during the root canal filling.

Long-term (3 months) $\mathrm{CH}$ medication was used in the treatment of this case because intracanal exudation was present at the patient's 2-month visit. The advantages

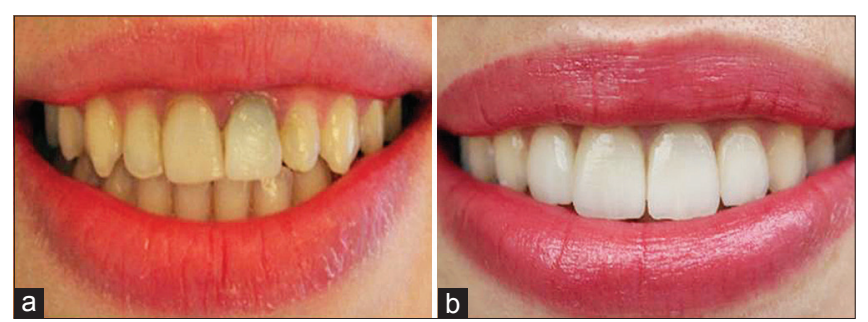

Figure 3: (a) Mineral trioxide aggregate discoloration in the crown. (b) Esthetic appearance after prosthetic restoration

of long-term $\mathrm{CH}$ dressings are its antibacterial effect on the intracanal bacteria and its possible necrotizing effect on the internal inflammatory resorptive tissue, which is similar to its coagulation necrosis effect on the exposed pulp tissue due to its high $\mathrm{pH} .{ }^{[9]}$ However, long-term $\mathrm{CH}$ medication may cause a significant decrease in the fracture resistance of teeth roots. ${ }^{[9]}$

The disadvantages of orthograde MTA canal filling in perforating internal resorption cases might be coronal discoloration, extrusion from the perforation, and inadequate marginal adaptation around the root defects. The coronal discoloration due to the MTA canal filling was seen in this case.

The advantages of MTA are good sealing ability, biocompability, physical durability, and low-grade and long-term $\mathrm{CH}$ release. MTA was shown to allow proliferation of periodontal cells and cementoblast over itself in animal and cell culture studies. ${ }^{[10,11]}$ The deposition of a hard tissue around the MTA filling in the perforation defect was present initially at the 6-month follow-up radiographies of the present case. Furthermore, a hard tissue barrier was evident at 4 and 6 years, repairing the defected root surface. This hard tissue barrier might be cementum, proliferating from the adjacent root surfaces. One-year orthodontic treatment did not appear to cause an adverse effect on the tooth root in the present case.

\section{Financial support and sponsorship \\ Nil.}

\section{Conflicts of interest}

There are no conflicts of interest.

\section{REFERENCES}

1. Gabor C, Tam E, Shen Y, Haapasalo M. Prevalence of internal inflammatory root resorption. J Endod 2012;38:24-7.

2. Patel S, Ricucci D, Durak C, Tay F. Internal root resorption: A review. J Endod 2010;36:1107-21

3. Nilsson E, Bonte E, Bayet F, Lasfargues JJ. Management of internal root resorption on permanent teeth. Int J Dent 2013;2013:929486.

4. Nunes E, Silveira FF, Soares JA, Duarte MA, Soares SM. Treatment of perforating internal root resorption with MTA: A case report. J Oral 
Sci 2012;54:127-31.

5. Bhuva B, Barnes JJ, Patel S. The use of limited cone beam computed tomography in the diagnosis and management of a case of perforating internal root resorption. Int Endod J 2011;44:777-86.

6. Brito-Júnior M, Quintino AF, Camilo CC, Normanha JA, Faria-e-Silva AL. Nonsurgical endodontic management using MTA for perforative defect of internal root resorption: Report of a long term follow-up. Oral Surg Oral Med Oral Pathol Oral Radiol Endod 2010;110:784-8.

7. Takita T, Tsurumachi T, Ogiso B. Endodontic treatment of a maxillary lateral incisor with a perforating internal resorption by using cone beam computed tomography as a diagnostic aid: A case report. Quintessence Int 2011;42:745-52.
8. Altundasar E, Demir B. Management of a perforating internal resorptive defect with mineral trioxide aggregate: A case report. J Endod 2009;35:1441-4.

9. Mohammadi Z, Dummer PM. Properties and applications of calcium hydroxide in endodontics and dental traumatology. Int Endod J 2011;44:697-730.

10. Baek SH, Plenk H Jr., Kim S. Periapical tissue responses and cementum regeneration with amalgam, SuperEBA, and MTA as root-end filling materials. J Endod 2005;31:444-9.

11. Güven EP, Taşlı PN, Yalvac ME, Sofiev N, Kayahan MB, Sahin F, et al. In vitro comparison of induction capacity and biomineralization ability of mineral trioxide aggregate and a bioceramic root canal sealer. Int Endod J 2013;46:1173-82. 